\title{
Economic comparison of transverse and longitudinal flow hollow fiber membrane modules for reverse osmosis and ultrafiltration
}

\author{
H. Futselaar, R.J.C. Zoontjes, T. Reith and I.G. Rácz* \\ University of Twente, Department of Chemical Engineering, P.O. Box 217, \\ NL-7500 AE Enschede (The Netherlands)
}

SUMMARY

The presently used hollow fiber membrane modules consist of a bundle of fibers in a cylindrical polymer or metal shell parallel to the shell axis. The feed solution flows either through the lumen or at the outside parallel to the fibers. This paper compares the performance of these modules with a new transverse flow module where the hollow fibers are positioned perpendicularly to the flow direction. For both types of modules the product costs are calculated for desalination by reverse osmosis and Dextran concentration by ultrafiltration. These calculations are based on literature data. The main conclusion is that the application of the tr'ansverse flow module is only attractive if the permeation resistance is mainly determined by the hydrodynamics (ultrafiltration) and not attractive if the membrane permeability is the main resistance (reverse osmosis).

Key words: module design, hollow fiber membranes, transverse flow, reverse osmosis and ultrafiltration, economics

\footnotetext{
*To whom correspondence should be addressed.
}

Presented at the ACS Symposium on Advances in Membrane Separation Science and Technology, San Francisco, April 5-10, 1992.

0011-9164/93/\$06.00 (C) 1993 Elsevier Science Publishers B.V. All rights reserved. 


\section{SYMBOLS}

$a^{*} \quad$ - proportionality constant (bar)

$A \quad-\operatorname{area}\left(\mathrm{m}^{2}\right)$

$A^{*} \quad-$ membrane permeability of the solvent $\left(\mathrm{m} \cdot \mathrm{s}^{-1} \cdot \mathrm{bar}^{-1}\right)$

$b^{*} \quad$ - osmotic pressure coefficient $\left(\right.$ bar $\left.\cdot \mathrm{m}^{3} \cdot \mathrm{kg}^{-1}\right)$

$B$ - solute permeability $\left(\mathrm{m} \cdot \mathrm{s}^{-1}\right)$

C - concentration $\left(\mathrm{kg} \cdot \mathrm{m}^{-3}\right)$

$d \quad$ - hollow fiber diameter (m)

$d^{*} \quad$ - characteristic diameter $(\mathrm{m})$

D - module diameter (m)

$D^{*}$ - diffusion coefficient $\left(\mathrm{m}^{2} \cdot \mathrm{s}^{-1}\right)$

$F \quad$ - driving force (varying)

$J \quad-$ flux $\left(\mathrm{m}^{3} \cdot \mathrm{m}^{-2} \cdot \mathrm{h}^{-1}\right)$

$k \quad-$ mass transfer coefficient $\left(\mathrm{m} \cdot \mathrm{s}^{-1}\right)$

$k_{c} \quad-\operatorname{cost}$ of capital $\left(\mathrm{Hfl} \cdot \mathrm{m}^{-2} \cdot \mathrm{h}^{-1}\right)$

$k_{p} \quad$ - cost of pumping energy delivered to the fluid $\left(\mathrm{Hfl} \cdot \mathrm{kWh}^{-1}\right)$

$k_{t} \quad-$ total product cost $\left(\mathrm{Hfl} \cdot \mathrm{m}^{-3}\right)$

$K \quad$ - operating cost per unit time $\left(\mathrm{Hfl} \cdot \mathrm{h}^{-1}\right)$

$L \quad$ - length of the module (m)

$n \quad-$ solution-dependent constant $(-)$

$\Delta P$ - pressure-drop (bar)

$Q \quad$ - flow rate $\left(\mathrm{m}^{3} \cdot \mathrm{h}^{-1}\right)$

$R \quad$ - resistance (varying)

$R e$ - Reynolds number (-)

$s_{1} \quad-$ longitudinal pitch (m)

$s_{\mathrm{t}} \quad-\operatorname{transverse}$ pitch $(\mathrm{m})$

Sc - Schmidt number (-)

Sh - Sherwood number (-)

$v \quad-$ velocity $\left(\mathrm{m} \cdot \mathrm{s}^{-1}\right)$

$X \quad$ - weight fraction (-)

\section{Greek}
$\varepsilon \quad-$ porosity (-)
$\eta \quad$ - dynamic viscosity $(\mathrm{Pa} \cdot \mathrm{s})$
$\xi \quad$ - pressure-drop coefficient (-)
$\rho \quad-$ density $\left(\mathrm{kg} \cdot \mathrm{m}^{-3}\right)$ 


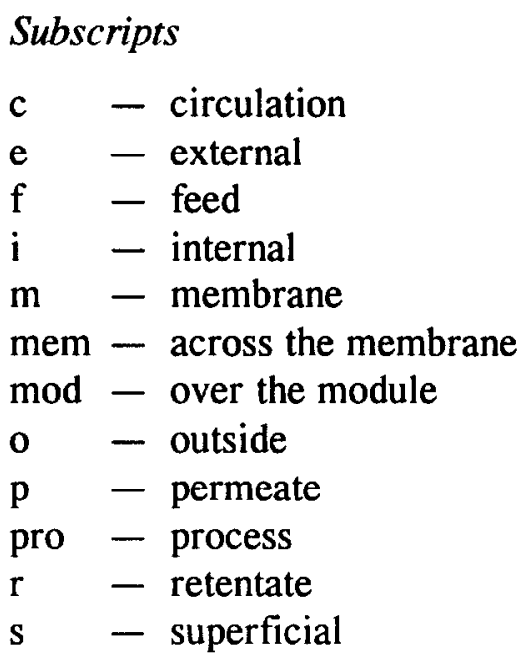

\section{Abbreviations}

LFI - lumen flow module (inside)

LFO - longitudinal flow module (outside)

TPS - transverse flow module (parallel staggered packed)

\section{INTRODUCTION}

Compared to tubular, plate-and-frame, or spiral-wound membrane modules, hollow fiber membrane modules have the advantage of a high specific membrane area (in the order of $1,000-10,000 \mathrm{~m}^{2} / \mathrm{m}^{3}$ compared to $100-300,200-400$, or $300-1,000 \mathrm{~m}^{2} / \mathrm{m}^{3}$, respectively). However, one disadvantage of the commercially used types is the difficulty to enlarge the mass transfer by means of turbulence promoters. In the case of lumen flow modules (where the feed flow is through the lumen of the fibers) or in the case of the longitudinal flow module (where the feed flow is at the outside and parallel to the fiber axis), it is not possible to introduce fluidizing particles, static mixing elements, spacers, or corrugated membranes. The only way to increase the turbulence is to enlarge the feed flow rate or basically to change the module design.

A considerable enhancement of the mass-transfer can be obtained by positioning the fibers perpendicular to the flow direction, which results in turbulence promotion by the membrane fibers themselves. This principle has been already successfully applied to cross-flow heat-exchangers. In this case 
we prefer the term "transverse flow" to indicate that the feed flow is perpendicular to the fiber axis because "cross-flow" has a different meaning in membrane technology. The application of the transverse flow in hollow fiber membrane modules is described in the patent literature [1-4]. At this moment the transverse flow membrane module is not commercially available and its application has only been investigated on a laboratory scale [5-8].

The transverse flow membrane module contains a more or less regular package of fiber grids, comparable with the parallel or crossed packed tubebanks in a cross-flow heat-exchanger (Fig. 1). For mechanical reasons the crossed packed configuration is preferable. The fibers are not as stiff as the tubes in heat-exchangers; thus the feed solution flowing past the fibers bends these in the flow direction. If the successive fiber grids are in a crossed configuration, the fibers support each other with a minimum of touching; this instead of the parallel packed configuration where the fibers can touch each other over the whole length (see also Fig. 3.).

It is the purpose of this study to present an economic comparison of both modules for two separations: desalination by reverse osmosis (RO) and Dextran concentration by ultrafiltration (UF). For this purpose the necessary data for mass transfer and pressure-drop have been derived from the literature.

The lumen and longitudinal flow membrane module have widely been investigated and modeled for liquid systems and several relations for describing the mass transfer are available. However, the mass transfer in the transverse flow membrane module has only been studied in a randomly packed fiber bundle placed transversely to the flow [5]. This design is not similar to ours, so the mass transfer correlations derived are not applicable to the module construction we have developed.

More data about the overall transfer of heat and momentum in transversely packed cylindrical tube-banks can be deduced from the heat-exchanger literature where an abundance of cross-flow heat-exchanger data have been published. However, direct measurements of momentum and mass transfer in crossed packed tube-banks resulting in reliable design correlations have not yet been reported in the literature. Therefore for all the module types we use the momentum and the heat transfer correlations as they are applied in the design of heat-exchangers.

In a future study [9] momentum and mass transfer measurements will be presented for the transverse flow modules and general design correlations will be derived. 


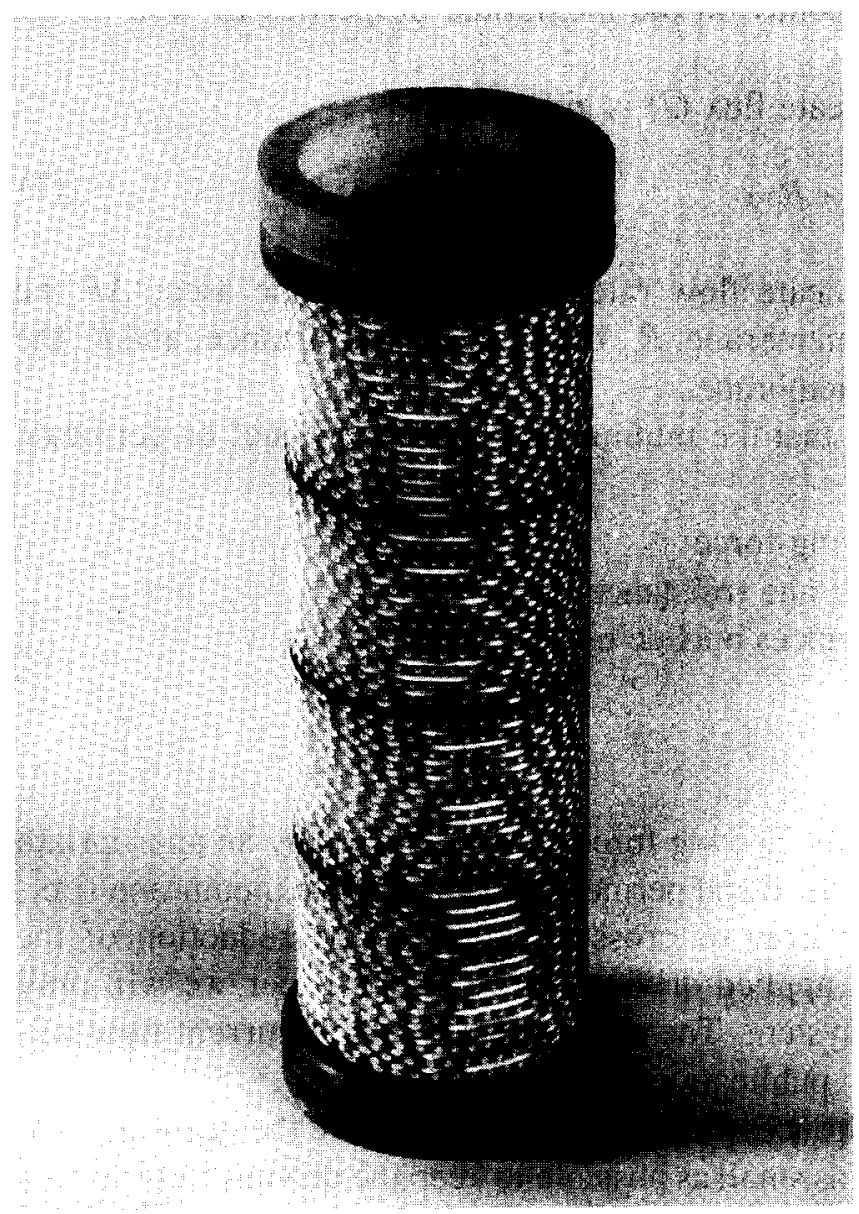

Fig. 1. The transverse flow hollow fiber membrane module (microfiltration; $0.5 \mathrm{~m}^{2}$ membrane area).

\section{THEORY}

\section{General considerations}

The performance of a separation unit is determined by its selectivity and its capacity. For membrane separation processes the selectivity is defined as the ratio of the component concentration in the permeate stream to that in the feed stream. This selectivity is mainly determined by the properties of the 
membrane. The capacity is defined by the amount permeate produced per volume apparatus. It depends on the membrane properties as well as the process conditions.

The capacity or permeate flux $(J)$ is given by

$$
J=Q_{\mathrm{p}} / A_{\mathrm{m}}=\Delta F /\left(R_{\mathrm{m}}+R_{\mathrm{o}}\right)
$$

in which $Q_{\mathrm{p}}$ is the permeate flow rate, $A_{\mathrm{m}}$ the membrane area, $\Delta F$ the driving force across the membrane, $R_{\mathrm{m}}$ the membrane resistance, and $R_{\mathrm{o}}$ the resistances outside the membrane.

Eqn. (1) makes clear that the minimization of the product or permeate cost is realized by:

- increasing the driving force

- reducing the membrane resistance

- reducing the resistances outside of the membrane

\section{Driving force}

The maximization of the driving force can be realized by an appropriate flow configuration of the feed and permeate flow along the membrane (i.e., countercurrent/cocurrent flow or cross-flow) or by the reduction of the forces counteracting the applied driving force. In this paper we will only consider the cross-flow system. The application of countercurrent flow will be the subject of another publication [9].

For pressure-driven processes the pressure-drops at the feed and the permeate side have to be as small as possible to keep the driving force across the membrane at its initial level. However, increasing the mass transfer is always related to an increase in the pressure-drop.

\section{Resistances}

The resistances can consist of (depending on the membrane process):

- membrane resistance

- resistance caused by adsorption

- resistance caused by pore-blocking

- resistance caused by the formation of a gel layer

- resistance caused by the concentration polarization

The membrane resistance depends on the membrane thickness, the structure of the membrane matrix, and on the interaction between the permeating 
components and the membrane material, or in the case of the presence of pores on the pore diameter, the porosity and the tortuosity. The adsorption resistance depends on the properties of the solutes in the feed flow and the membrane material. The module designer has taken into account this resistance, but besides periodic cleaning has no means to oppose it. The elimination of the pore-blocking resistance is again the responsibility of the membrane manufacturer in order to develop a membrane with "selfcleaning" pores. The formation of a gel layer occurs in macromolecular systems if the gel concentration is reached. Both the membrane manufacturer and the module designer can influence this resistance.

The minimization of concentration polarization resistance is a major concern for the module designer. In this paper only the effect of this resistance will be discussed.

\section{Concentration polarization and module design}

Concentration polarization is the phenomenon of the accumulation of the rejected solutes (ions, macromolecules, suspended particles) near the membrane. The accumulation is the net effect of a convective stream from the bulk of the feedstream to the membrane (caused by the driving force across the membrane) and a "diffusive" stream from the membrane back to the bulk flow (caused by the concentration gradient or by shear-induced back-diffusion). The influence of this accumulation is a reduction in the flux through the membrane and a change in the separation selectivity.

A measure for this accumulation is the ratio of the total resistance over the membrane and the fluid boundary layers and the membrane resistance itself. For the present state hollow fiber membrane modules these resistance ratios are:

- reverse osmosis

: $1.5-2.0$

- ultrafiltration

: $5-10$

- microfiltration

: $10-50$

Concentration polarization can be decreased by increasing the interaction between the boundary layer and the bulk solution by the application of auxiliary means such as the enlargement of the feed flow velocity, the use of static mixers, the rotation of the membranes, the application of pulsating flow, or the principle of a fluidized bed. Our laboratory has developed an alternative method, viz. the application of the membrane itself as the turbulence promoter such as the corrugated flat and tubular membrane module [10-13] or as discussed in this paper the transverse flow capillary and hollow fiber membrane module. 
Costs

Our cost comparison is based on a circulation system which handles liquid solutions with pressure-driven membrane processes (RO, UF) (Fig. 2.). The feed solution $\left(Q_{\mathrm{f}}\right)$ is pressurized up to the process pressure $\left(\Delta P_{\text {pro }}\right)$ by a high-pressure pump. The circulation pump provides at a pressure difference over the module $\left(\Delta P_{\text {mod }}\right)$ the required feed flow rate $\left(Q_{\mathrm{c}}\right)$ along the membrane surface $\left(A_{\mathrm{m}}\right)$. An energy recovery system is not considered. In operating this system three cost factors have to be considered: the cost of capital which is to be assumed proportional to the membrane area, the cost to pressurize the feed solution, and the cost required to circulate the solution over the membrane surface. The operating cost per unit time is expressed as

$$
K=k_{\mathrm{c}} \cdot A_{\mathrm{m}}+k_{\mathrm{p}} \cdot\left[\Delta P_{\mathrm{pro}} \cdot Q_{\mathrm{f}}+\Delta P_{\text {mod }} \cdot Q_{\mathrm{c}}\right]
$$

with $k_{\mathrm{p}}$ is the cost of pumping energy delivered to the fluid and $k_{\mathrm{c}}$ the cost of capital per unit operational time per unit membrane area. The total product cost per unit volume permeate $\left(J \cdot A_{\mathrm{m}}\right)$ is given by

$$
k_{\mathrm{t}}=\frac{K}{J \cdot A_{\mathrm{m}}}=\frac{k_{\mathrm{c}}}{J}+\frac{k_{\mathrm{p}}}{J \cdot A_{\mathrm{m}}} \cdot\left[\Delta P_{\mathrm{pro}} \cdot Q_{\mathrm{f}}+\Delta P_{\text {mod }} \cdot Q_{\mathrm{c}}\right]
$$

The use of Eqn. ( $2 b$ ) requires correlations to describe the permeate flux, the mass transfer, and the pressure drop over the membrane module.

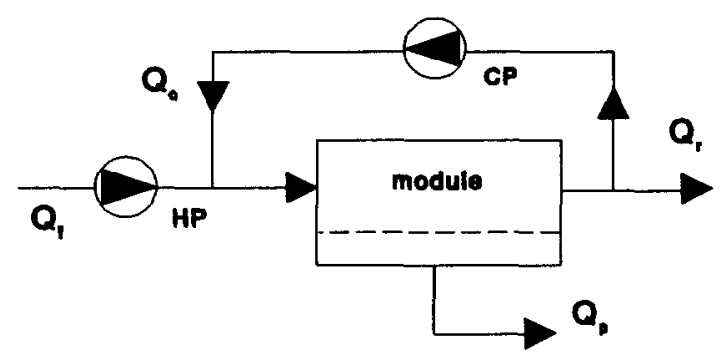

Fig. 2. A circulation system (HP: high-pressure pump, CP: circulation pump).

Flux models

For RO concentration polarization manifests itself by the reduction of the effective trans-membrane pressure difference by the enhanced osmotic pres- 
sure difference while for UF it causes a flattening of the flux-pressure curve, finally leading to a pressure-independent flux. For the permeate flux of RO, Rautenbach et al. [14] deduced

$J=A^{*} \cdot\left(\Delta P_{\text {mem }}-b^{*} \cdot\left(C_{\mathrm{f}}-\frac{B \cdot C_{\mathrm{f}} \exp (J / k)}{J+B \cdot \exp (J / k)} \cdot \exp (J / k)\right)\right]$

in which $A^{*}$ is the membrane permeability for the solvent, $\Delta P_{\text {mem }}$ the transmembrane pressure difference, $b^{*}$ the osmotic pressure coefficient, $B$ the solute permeability, $C_{\mathrm{f}}$ the feed concentration, and $k$ the mass transfer coefficient.

Wijmans et al. [15] described the UF of medium weight solutes $(10,000-$ 100,000 Dalton) by the osmotic pressure model

$J=A^{*} \cdot\left(\Delta P_{\mathrm{mem}}-a^{*} \cdot X_{\mathrm{f}}^{n} \cdot \exp (n J / k)\right)$

with $a^{*}$ is a proportionality constant, $X_{\mathrm{f}}$ the solute concentration (weight fraction), and $n$ is a solution-dependent constant.

\section{Mass transfer and pressure-drop correlations}

For the mass transfer coefficient in the case of the inside and outside flow transfer correlations have been used, which have originally been derived for heat transfer in shell and tube heat-exchangers (e.g., Rautenbach et al. [14]):

$$
S h=3.66+1.61\left(\operatorname{Re} \cdot S c \cdot d^{*} / L\right)^{1 / 3}
$$

for the laminar flow regime and

$$
S h=0.023 R e^{7 / 8} S c^{1 / 4}
$$

for the turbulent flow regime. The characteristic diameter $d^{*}$ is defined as four times the cross-sectional area divided by the wetted perimeter.

The pressure-drop correlation for these both types of hollow fiber modules has also been derived from the shell and tube heat-exchangers

$$
\Delta P=\xi \cdot 1 / 2 \rho v_{\mathrm{s}}^{2} \cdot L / d^{*}
$$

with 
$\begin{array}{ll}\xi=64 / R e & R e< \pm 3000 \\ \xi=0.3164 / R e^{0.25} & \pm 3000<\operatorname{Re}<1 \times 10^{5}\end{array}$

Although the principle of the transverse flow module was already patented in 1967, no commercial module is available on the market. As explained in the introduction this configuration has a lot in common with the cross-flow heat-exchanger. In the case of the heat-exchangers four basic configurations are distinguished (Fig. 3):

- parallel in-line

- parallel staggered

- crossed in-line

- crossed staggered
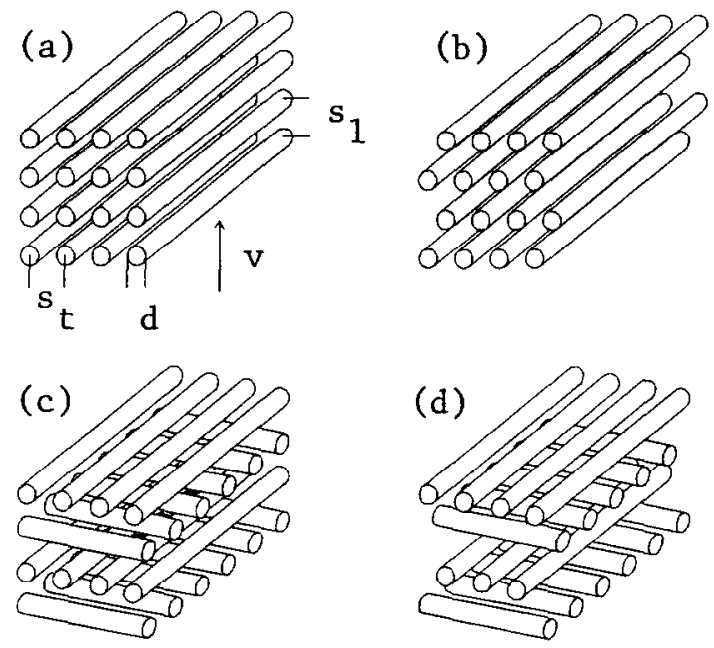

Fig. 3. Main packed configurations; (a) parallel in-line, (b) parallel staggered, (c) crossed in-line, (d) crossed staggered.

Many investigations have been reported on the transfer of heat and momentum in transversely packed tube-banks. Especially the parallel packed configurations have widely been investigated and a lot of general correlations are known [16, 17]. But as explained in the introduction the crossed packed configurations are to be preferred because of mechanical reasons. Although in the literature a number of crossed packed configurations has been investigated [18-21] no general correlations for momentum and mass transfer have been derived in the low Reynolds number regime $(R e \leq$ 


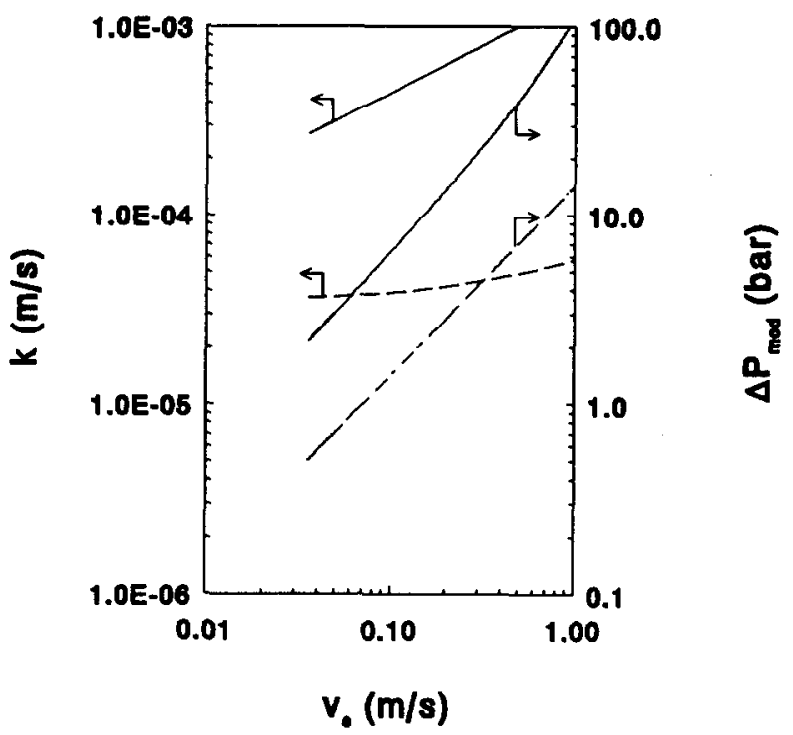

Fig. 4. Mass transfer and pressure-drop as a function of the superficial velocity (RO; TPS $\longrightarrow$, LFO - - ).

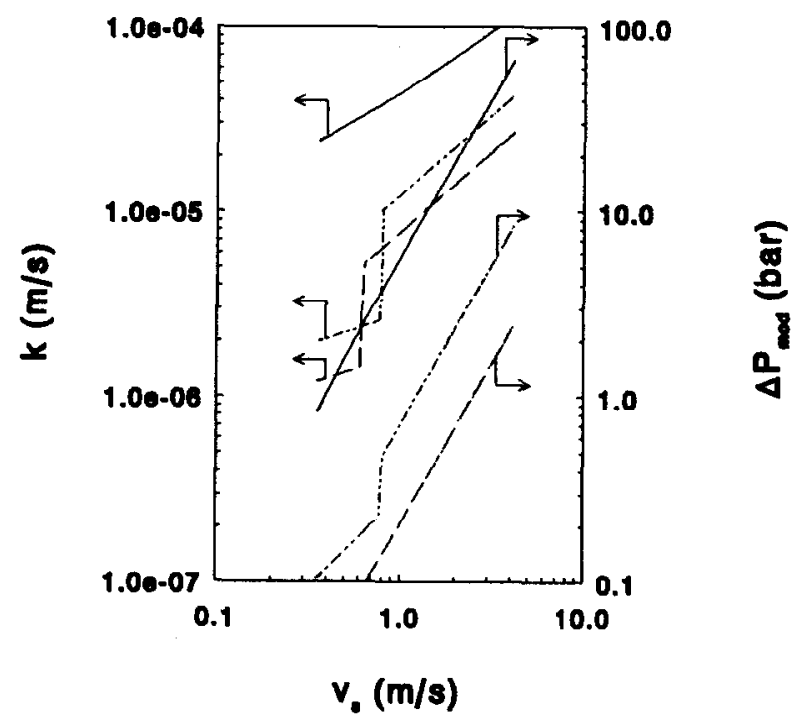

Fig. 5. Mass transfer and pressure-drop as a function of the superficial velocity (UF; TPS $\longrightarrow$, LFO - - LFI -...). 
\pm 1000 ). Therefore we apply in this study the heat and momentum transfer correlations for the parallel staggered packed configuration as a reasonable approximation. For the design equations themselves we refer to the literature $[16,17]$ because they do not have the simple forms such as Eqns. (5)-7).

Figs. 4 and 5 show the mass transfer coefficients and the pressure-drop over the module for the different types of modules. The relevant process and module data are listed in Tables I and II. For RO the mass transfer coefficient in the transverse flow is at least a decade greater than in the present state hollow fiber membrane modules; for UF this enlargement is at least a factor of 5. However, the advantage of the enlarged mass transfer is determined by the ratio of the outside and inside membrane resistances.

The trans-membrane pressure $\left(\Delta P_{\text {mem }}\right)$ in the flux Eqns. (3) and (4) is taken to be equal to

$$
\Delta P_{\text {mem }}=\Delta P_{\text {pro }}-1 / 2 \cdot \Delta P_{\text {mod }}
$$

All the process parameters in Eqn. (2b) are now available enabling an economic comparison of the hollow fiber membrane modules.

\section{APPLICATION}

\section{Reverse osmosis}

We consider a reverse osmosis process with an aqueous salt solution applying the longitudinal flow module and the transverse flow module. The internal diameter of the fibers can be small because the permeate flux is relatively low. For a $1.0 \mathrm{~m}$ long radial flow module Rautenbach et al. [14] found a maximal productivity per unit module volume with fibers of an internal diameter of $50 \mu \mathrm{m}$ and an external one of $100 \mu \mathrm{m}$. For this study these sizes are adequate.

At given porosity, module diameter, and feed flow rate the module length is used as the design parameter to obtain the required recovery $\left(Q_{\mathrm{p}} / Q_{\mathrm{f}}\right)$.

The cost of capital includes the cost of the extra modules, the spare parts, space requirements, maintenance, chemicals, filters and the investment costs. Rautenbach [14] presents some economic data of a seawater RO plant using longitudinal flow modules. The cost of capital is $\mathrm{Hfl} 0.078 / \mathrm{m}^{2} \cdot \mathrm{h}$ in which the modules cost contributes about $15 \%$. Although the transverse flow module is not (yet) commercially available, we have developed a production 


\section{TABLE I}

Process data

\begin{tabular}{|c|c|c|}
\hline & Reverse osmosis & Ultrafiltration \\
\hline \multicolumn{3}{|l|}{ Feed solution: } \\
\hline$Q_{\mathrm{f}}\left(\mathrm{m}^{3} \cdot \mathrm{h}^{-1}\right)$ & 1.0 & 10.0 \\
\hline$C_{\mathrm{f}}\left(\mathrm{kg} \cdot \mathrm{m}^{-3}\right)$ & $40.0(\mathrm{NaCl})$ & 10.0 (Dextran) \\
\hline$\rho\left(\mathrm{kg} \cdot \mathrm{m}^{-3}\right)$ & $1.02 \times 10^{3}$ & $1.01 t 10^{3}$ \\
\hline$\eta(\mathrm{Pa} \cdot \mathrm{s})$ & $1.01 \times 10^{-3}$ & $1.0 \times 10^{-3}$ \\
\hline$D^{*}\left(\mathrm{~m}^{2} \cdot \mathrm{s}^{-1}\right)$ & $1.5 \times 10^{-9}$ & $5.0 \times 10^{-11}$ \\
\hline \multicolumn{3}{|l|}{ Operating conditions: } \\
\hline$\Delta P_{\text {pro }}($ bar $)$ & 50.0 & 5.0 \\
\hline$b^{*}\left(\mathrm{bar} \cdot \mathrm{m}^{3} \cdot \mathrm{kg}^{-1}\right)$ & 0.853 & - \\
\hline$a^{*}$ (bar) & - & 100.0 \\
\hline$n(-)$ & - & 2 \\
\hline recovery $(\%)$ & 80 & 15 \\
\hline \multicolumn{3}{|l|}{ Costs: } \\
\hline$k_{\mathrm{p}}(\mathrm{Hfl} / \mathrm{kWh})$ & 0.15 & 0.15 \\
\hline \multirow{2}{*}{$k_{\mathrm{c}}\left(\mathrm{Hfl} /\left(\mathrm{m}^{2} \cdot \mathrm{h}\right)\right.$} & 0.084 & 0.25 \\
\hline & 0.078 & 0.20 \\
\hline \multicolumn{3}{|l|}{ Pump efficiencies: } \\
\hline High pressure (\%) & 75 & 75 \\
\hline Circulation (\%) & 75 & 75 \\
\hline
\end{tabular}

method for modules up to $1.0 \mathrm{~m}^{2}$ and we estimate the additional manufacturing cost up to $50 \%$ maximally. For the transverse flow this cost is then $\mathrm{Hfl} 0.084 / \mathrm{m}^{2} \cdot \mathrm{h}$. Presently the electrical energy cost is about $\mathrm{Hfl} 0.15 / \mathrm{kWh}$. The pump efficiencies are considered to be $75 \%$. Table I summarizes the process data and Table II presents module specific data.

\section{Ultrafiltration}

In the case of UF a Dextran solution is filtered using the lumen, the longitudinal and the transverse flow module. Hollow fiber sizes for UF modules lie in the range $0.25-1.5 \mathrm{~mm}$ (internal) and $0.4-3.0 \mathrm{~mm}$ (external), also dependent on the module type. For the sake of convenience, we have taken the dimensions for all the types the same $2.0 \mathrm{~mm}$ (external) and 
TABLE II

Geometrical data for the transverse flow (TPS), the longitudinal flow (LFO) and the lumen flow (LFI) module

\begin{tabular}{|c|c|c|c|c|c|}
\hline & \multicolumn{2}{|c|}{ Reverse osmosis } & \multicolumn{3}{|c|}{ Ultrafiltration } \\
\hline & TPS & LFO & TPS & LFO & LFI \\
\hline \multicolumn{6}{|l|}{ Fiber geometry: } \\
\hline$d_{\mathrm{c}}(\mathrm{mm})$ & 0.10 & 0.10 & 2.0 & 2.0 & 2.0 \\
\hline$d_{\mathrm{i}}(\mathrm{mm})$ & 0.05 & 0.05 & 1.5 & 1.5 & 1.5 \\
\hline \multicolumn{6}{|l|}{ Membrane properties: } \\
\hline$A^{*}\left(\mathrm{~m} \cdot \mathrm{s}^{-1} \cdot \mathrm{bar}^{-1}\right)$ & \multicolumn{2}{|c|}{$2.0 \times 10^{-7}$} & \multicolumn{3}{|c|}{$2.8 \times 10^{-5}$} \\
\hline$B\left(\mathrm{~m} \cdot \mathrm{s}^{-1}\right)$ & \multicolumn{2}{|c|}{$1.0 \times 10^{-7}$} & \multicolumn{3}{|c|}{-} \\
\hline \multicolumn{6}{|l|}{ Module properties: } \\
\hline$s_{\mathrm{t}} / \mathrm{d}$ & 2.0 & - & 2.0 & - & - \\
\hline$s_{\mathrm{l}} / \mathrm{d}$ & 1.04 & - & 1.04 & - & - \\
\hline$D(\mathrm{~m})$ & 0.1 & 0.1 & 0.1 & 0.1 & 0.1 \\
\hline$\varepsilon(\%)$ & 61 & 61 & 61 & 61 & 61 \\
\hline$L(\mathrm{~m})$ & 0.60 & 0.64 & 0.91 & 1.15 & 0.80 \\
\hline$A_{\mathrm{m}}\left(\mathrm{m}^{2}\right)$ & 71.4 & 79.0 & 5.4 & 7.1 & 6.6 \\
\hline
\end{tabular}

$1.5 \mathrm{~mm}$ (internal). A rule of thumb for the contribution of the module price in the cost of capital is about $50 \%$ for an UF unit up to several square meters of membrane area and about $30 \%$ for plants with more than $100 \mathrm{~m}^{2}$ of membrane area. Based on a module price of $\mathrm{Hfl} 1000 / \mathrm{m}^{2}$ and a lifetime of $10,000 \mathrm{~h}$, we assume the cost of capital of the presently used modules to lie in the range $\mathrm{Hfl} 0.20-0.33 / \mathrm{m}^{2} \cdot \mathrm{h}$. For the transverse flow module this cost will be in the order of $\mathrm{Hfl} 0.25-0.38 / \mathrm{m}^{2} \cdot \mathrm{h}$. Table I presents the process parameters and Table II the module data.

Figs. 6 and 7 show the the permeate flow rates and the product costs for the different types of hollow fiber modules as a function of the superficial velocity. For a wide velocity range the permeate flow rates of both modules are more or less independent of the superficial velocity. Both RO modules reach their maximal productivity at a velocity in which the circulation flow can be neglected. The only possibility to increase the productivity is to use more permeable membranes. However, the presently available hollow fiber membranes have permeabilities which are certainly not higher than used in this study. In the case of UF the influence of the hydrodynamics and the 


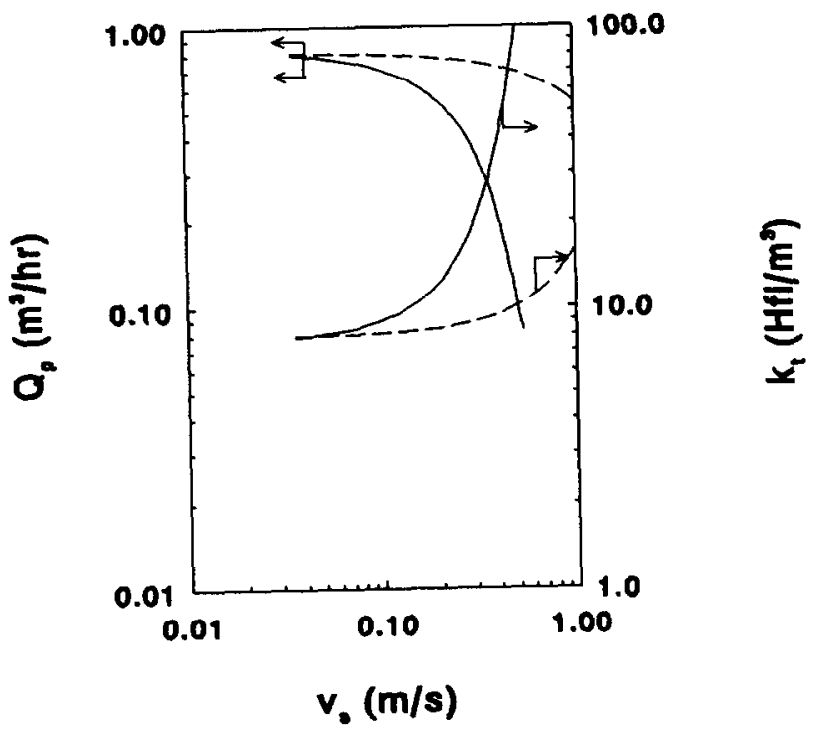

Fig. 6. Permeate flow rate and product cost as a function of the superficial velocity (RO; TPS - , LFO - -).

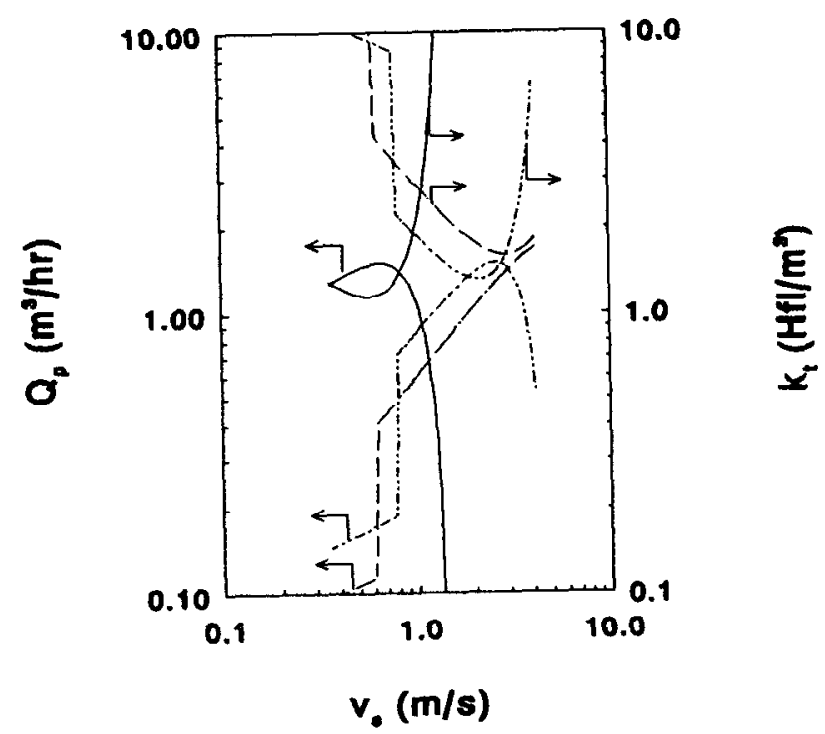

Fig. 7. Permeate flow rate and product cost as a function of the superficial velocity (UF; TPS — , LFO - - LFI -... -). 
module geometry is more evident. For the transverse flow module the ratio between the circulation and the feed flow rate is $0.7,8.3$ for the longitudinal flow module, and 2.3 for the lumen flow module. It can be expected that in the case of microfiltration the hydrodynamics have even more influence on the permeate flow rate. Preliminary results have been presented in another paper [8].

Associating these permeate flow rate curves with the cost coefficients presented in Table I, the product cost can be calculated using Eqn. (2b). Table III presents the minimal product costs to realize a recovery of $80 \%$ for RO and $15 \%$ for UF. The minimal product costs for the RO modules are only determined by the permeation properties of the membrane and by the pressurization cost of the feed solution. The strong rise in the case of the transverse flow module is caused by the strong increase in pressure drop over the module at higher velocities. In the case of UF the lower product cost for the transverse flow modulc is caused by a higher permeate flux at a lower superficial velocity, resulting in a smaller membrane area and lower circulation pumping cost.

\section{TABLE III}

Minimal product cost per cubic meter permeate $\left(\mathrm{Hfl} / \mathrm{m}^{3}\right)$ at given recovery (Table I) and with the module length as a design parameter (Table II)

\begin{tabular}{lll}
\hline & Reverse osmosis & Ultrafiltration \\
\hline Transverse flow & 7.87 & 1.15 \\
Longitudinal flow & $7.96(+1.1 \%)$ & $1.63(+41 \%)$ \\
Lumen flow & - & $1.36(+18 \%)$ \\
\hline
\end{tabular}

\section{CONCLUSIONS}

In the literature the economics of transverse flow modules have been compared with those of other modules. Up to now this comparison was not based on actual cost of transverse flow modules. We have been able to determine these cost data by developing and producing transverse flow modules in our laboratory [9].

The application of the transverse flow module is only attractive if the permeation resistance is determined by the fluid boundary layers and not by the membrane. With the present-day RO hollow fiber membranes the 
permeation resistance is totally determined by the membrane, so the use of the transverse flow module does not lead to significant cost reduction. However, for UF the application of the transverse flow module will result in a saving of at least $15 \%$ of the product cost.

\section{ACKNOWLEDGMENTS}

These investigations were supported by the Dutch Foundation for Technical Science (STW), by KSLA (Shell Research B.V., Amsterdam), and by X-Flow B.V. (Almelo, The Netherlands).

\section{REFERENCES}

1 J.G.A. Bitter, H. Futselaar and I.G. Rácz, European patent $91201658.4-, 1991$.

2 N.S. Strand, U.S. patent 3,342,729, 1967.

3 J. Baudet, M. Rochet, M. Salmon and B. Vogt, U.S. patent 3,993,816, 1976.

4 R.W. Nichols, U.S.patent 4,959,152, 1990.

5 M.-C. Yang and E.L. Cussler, AIChE Journal, 32(11) (1986) 1910-1916.

6 H. Stam, In: Future Industrial Prospects of Membrane Processes, L. Cecille and J.-C.Toussaint (Eds.), Proceedings of BRITE-symposium, Brussels, 1988, $135-152$.

7 C. Lipski and P. Côté, Environmental Progress, 9(4) (1990) 254-261.

8 F.N.M. Knops, H. Futseladar and I.G.Rácz, J. Membr. Sci., in press.

9 H. Futselaar, Ph.D. Thesis, University of Twente (Enschede), The Netherlands, unpublished.

10 I.G. Rácz, J. Groot Wassink, British patent application no. 8608053, 1986.

11 M.J. van der Waal and I.G. Rácz, J.Membr. Sci., 40 (1989) 243-260.

12 M.J. van der Waal, S. Stevanovic and I.G. Rácz, J.Membr. Sci., 40 (1989) 261-275.

13 M.J. van der Waal and I.G.Rácz, I' ${ }^{2}$-Procestechnologie, 7-8 (1990) 29-34 (in Dutch).

14 R. Rautenbach and R. Albrecht, Membrane Processes, Wiley, Chichester, 1989.

15 J.G. Wijmans, S. Nakao and C.A. Smolders, J. Membr. Sci., 20 (1984) 115-124.

16 V. Gnielinski, Forsch.Ing.-Wesen, 44(1) (1978) 15-25.

17 E.S. Gaddis and V. Gnielinski, Verfahrenstechnik, 17(7) (1983) 410-418.

18 A.L. London, J.W. Mitchell and W.A.Sutherland, Transactions of the ASME (Journal of Heat Transfer), 82 (1960) 199-213.

19 H. Brauer, Chemie-Ing.-Techn., 36(3) (1964) 247-260.

20 R. Klier, Int. J. Heat Mass Transfer, 7 (1964) 783-799.

21 K. Hammeke, E. Heinecke and F. Scholz, Int. J. Heat Mass Transfer, 10 (1967) 427-446. 